\title{
Linha de montagem: projeto interdisciplinar relacionando robótica com o estudo de funções matemáticas
}

\author{
Adiel Jamesson Santos da Silva', Paulo Vinícius Cabral Aureliano', \\ Ytalo Paulo Wilian da Silva ${ }^{1}$, Rodrigo L. Rodrigues ${ }^{1}$ \\ ${ }^{1}$ Universidade Federal Rural de Pernambuco, Campus Sede (UFRPE) \\ CEP: 52171-900 - Recife - PE - Brasil \\ \{adiel8404, paulo.c.aureliano, ytalo.ypw, rodrigomuribec\}@gmail.com
}

\begin{abstract}
The article reports the experience of the students of the Licenciatura degree in Computing and Mathematics of the Federal Rural University of Pernambuco, who are scholarship holders of PIBID, referring to the interdisciplinary teaching of Computing and Mathematics, using robotics as an aid to study the functions mathematics. The project in question is being developed at the state school Ministro Jarbas Passarinho with some students of the 1st B class throughout the first semester of 2019 and will be applied in the second semester to the other students of the school.
\end{abstract}

Resumo. $O$ artigo relata a experiência dos alunos dos cursos de Licenciatura em Computação e Matemática da Universidade Federal Rural de Pernambuco, os quais são bolsistas do PIBID, referente ao projeto de ensino interdisciplinar de Computação e Matemática, utilizando a robótica como auxílio para o estudo das funções matemáticas. $O$ projeto em questão está sendo desenvolvido na escola estadual Ministro Jarbas Passarinho com alguns alunos da turma do $1^{\circ} \mathrm{B}$ ao longo do primeiro semestre de 2019 e será aplicado em sala de aula no segundo semestre para os demais alunos da escola.

\section{Introdução}

O avanço tecnológico vem possibilitando o desenvolvimento de tarefas de forma cada vez mais rápida no cotidiano e a solucionar problemas. Segundo a SBC (Sociedade Brasileira de Computação) no documento divulgado sobre as Diretrizes para o ensino de Computação na Educação Básica (2019, p. 3):

é necessário desenvolver plenamente suas habilidades e conseguir utilizar a tecnologia digital de forma adequada [para isso] é necessário que cada pessoa compreenda o funcionamento do "mundo digital" da mesma forma que se tem entendimento do "mundo real" através das ciências da natureza e das ciências humanas.

Com isso, a tecnologia no ambiente educacional vem para contribuir no processo de aprendizagem dos alunos, para que eles sejam capazes de utilizar as ferramentas tecnológicas, trazendo os conhecimentos do mundo digital para solucionar os problemas do mundo real. 
A robótica educacional é um recurso de suma importância no processo de ensino aprendizagem do aluno, com ela podemos explorar os mais diversos conteúdo do currículo escolar de várias disciplinas de forma interdisciplinar que pode proporcionar a interação entre professores e alunos através de trabalhos concebidos e construídos em grupos que exploram diferentes competências intelectuais (MORAES, 2010).

A robótica é uma área que está em crescimento no momento, e estima-se que crescerá ainda mais ao longo dos anos, segundo WOLFGANG e col. (2017,p.1, tradução nossa):

O mercado global de robótica - o uso de robôs controlados por computador para realizar tarefas manuais - está crescendo muito mais rápido do que o esperado. Em 2014, o BCG projetou que o mercado atingiria US \$ 67 bilhões até 2025. Em 2017, aumentamos essa estimativa para US $\$ 87$ bilhões.

D’Ambrosio (1996, p. 13) nos fala um pouco sobre a importância da matemática se relacionar com as tecnologias:

Ao longo da evolução da humanidade, Matemática e tecnologia se desenvolveram em íntima associação, numa relação que poderíamos dizer simbiótica. A tecnologia entendida como convergência do saber (ciência) e do fazer (técnica), e a matemática são intrínsecas à busca solidária do sobreviver e de transcender. A geração do conhecimento matemático não pode, portanto ser dissociada da tecnologia disponível.

Todo esse crescimento vem despertando cada vez mais o interesse dos alunos pela tecnologia e conhecimento. Com campeonatos no Brasil e no mundo a robótica vem ganhando seu espaço nas escolas públicas brasileiras, por sua versatilidade e utilidade no ensino, proporcionando a multidisciplinaridade e integração de áreas do conhecimento, principalmente as áreas de matemática e informática que compartilham de uma mesma essência computacional, à solução de problemas.

Com base no supracitado pretendemos unir a matemática e a programação na construção de um robô que seja capaz de construir um automóvel lego, a partir de uma linha de montagem, utilizando o lego como instrumento de criação do projeto. Proporcionando aos alunos uma aprendizagem sobre robótica, programação, empreendedorismo e matemática. Essa aprendizagem de matemática se dá na atividade da administração financeira da empresa que será destrinchada no decorrer do trabalho.

\section{Fundamentação Teórica}

As tecnologias ocupam cada vez mais espaço na educação, hoje em dia qualquer estudante possui acesso a um dispositivo tecnológico, seja ele qual for, e a robótica está cada vez mais ganhando espaço entre estas tecnologias.

A robótica é de fato uma ferramenta que muda completamente o cenário da computação nas instituições escolares, possibilitando muitas vezes a emoção e a realização de criar algo a partir da programação, que por sua vez pode possuir uma utilidade no mundo real. Com base nisso, a robótica pode abrir várias janelas de conhecimento, de acordo com Zilli(2004, p. 39) "é uma ferramenta que permite ao professor demonstrar na prática muitos dos conceitos teóricos, às vezes de difícil compreensão, motivando o aluno, que a todo momento é desafiado a observar, abstrair e inventar", ou seja, a robótica é capaz de ajudar os alunos que possuem extrema dificuldade, que por vezes não conseguem entender o professor, 
mas com uma maior interatividade com essa tecnologia conseguem aprender com mais facilidade.

Seguindo a mesma linha de pensamento, algo que é de suma importância é instigar o instinto investigativo do aluno, promovendo a descoberta com o assunto que pode vir a enriquecê-lo intelectualmente, de acordo com LIRA et al. (2017, p. 5). "[...], o professor deve mostrar que os recursos tecnológicos são importantes para que o aluno aprenda, controle e explore as alternativas de resolução que a ferramenta oferece.”, ou seja, transmitir a informação através da robótica é uma alternativa fantástica, que permite trazer uma nova perspectiva do conteúdo para os alunos.

Percebe-se que a estratégia utilizada pelos alunos para realizar a programação é de "tentativa e erro". É uma forma mais demorada de encontrar os resultados esperados, mas ao mesmo tempo permite que os alunos analisem as diferentes possibilidades de programação e testem hipóteses (Maliuk, 2009, p.74).

De fato, apesar de não ser a mais eficiente a "tentativa e erro" possui seu valor muito forte nessa fase de aprendizado, pois é comum o erro e a cada erro cometido é algo que será relembrado, e dificilmente será cometido novamente, permitindo uma maior reflexão dos problemas encontrados e fixando o conhecimento. Com isso, a robótica educacional, segundo Barbosa (2015, p. 2) "proporciona aos envolvidos situações-problemas de diferentes magnitudes que devem ser superadas, com acertos, erros, até que se alcancem os objetivos desejados."

Dessa maneira podemos notar que os alunos possuem uma melhora na forma de resolver problemas, e isso está diretamente ligado com as habilidades do pensamento computacional, que segundo Silva $(2019$, p. 784$)$ "pode ser mais vantajoso, permitindo que os alunos tenham maior senso crítico e poder para resolução de problemas do cotidiano." O que vem sendo utilizado sem necessariamente o conhecimento dos envolvidos sobre o pensamento computacional.

\section{Metodologia}

As escolhas dos alunos participantes do projeto foram feitas por indicação da professora supervisora na escola. Como os alunos escolhidos são do turno da manhã, o projeto está sendo desenvolvido no contra turno de aula deles, no caso a tarde, onde temos $6 \mathrm{~h}$ de aulas por semana, dividido entre $3 \mathrm{~h}$ na segunda-feira e $3 \mathrm{~h}$ na quinta-feira, totalizando 24 horas mensais de atividade, dedicando uma hora em cada dia para planejamento das atividades. As aulas acontecem no laboratório de informática da escola, no qual tem disponível para uso os notebooks e Datashow.

\subsection{Introdução ao Pensamento Computacional}

Antes de começarmos as atividades introduzimos os alunos ao pensamento computacional para sabermos o nível de entendimento e afinidade computacional que os alunos possuíam. Primeiramente, explicamos o conceito de pensamento computacional e exemplificamos com situações do cotidiano, em seguida aplicamos uma atividade com duas questões, a primeira os alunos teriam que organizar roupas a serem lavadas em uma máquina de lavar, com roupas e 
cores diferentes, e a segunda era pedido para que organizassem caixas que possuíam peso, tamanho, e cor diferentes.

As questões foram aplicadas deixando livre a forma de organização feita pelos alunos, para que ao final as respostas fossem compartilhadas e discutidas com os demais alunos.

\subsection{Introdução ao Kit de Robótica Lego NXT}

Utilizando os kits de robótica disponibilizados pela escola os alunos construíram robôs educadores, robôs que foram feitos para o ensino e aprendizado das funções básicas da robótica lego.

Com os robôs construídos, começamos a introduzir as funcionalidades da programação lego, com o intuito de formar uma base com noção de programação para podermos prosseguir com a construção do produto do projeto. Nós propusemos aos alunos desafios de programação, para isso utilizamos o Manual Mindstorms Education do NXT 2.0 disponibilizado pelos órgãos públicos de Pernambuco, os desafios foram feitos levando em consideração o que havia sido explicado sobre a linguagem de programação em blocos da lego, os alunos completaram a atividade com destreza, demonstrando entendimento e compreensão do assunto.

\subsection{Trabalhando Matemática Financeira}

Primeiramente foi feito um teste de sondagem com os alunos do projeto abordando os conteúdos: juros (Simples e composto) e funções (definição de funções e função custo, lucro e receita). Como o resultado dos testes foi ruim, isto é, os alunos demonstraram baixo domínio do conteúdo, elaboramos atividades para poder revisar e exercitar esses conteúdos do teste de sondagem. Essa atividade é necessária pois trabalharemos esses conteúdos no decorrer do projeto.

Com os resultados da atividade aplicada, contextualizamos o conceito com a prática, simulando a criação de uma empresa fictícia de montagem de automóveis onde trabalhamos situações envolvendo os conteúdos em questão para facilitar a compreensão do assunto e entendimento da sua utilidade prática, utilizando de alguns exemplos recorrentes das indústrias como, compra e venda de peças, pagamento de encomendas com juros, custo de produção, administração de custos e lucros por meios de funções, entre outras atividades.

Com o robô foi possível fazer a contextualização do assunto, supondo uma indústria automobilística, no qual vários carros seriam produzidos e juros a serem trabalhados, atribuindo valores às partes e ao total do veículo, levando em consideração o tempo de produção e lotes a serem entregues à outras fábricas fictícias.

\subsection{Construção da Linha de Montagem e Programação}

Com os alunos construímos o robô que será o produto final do projeto, um braço robótico representando parte de uma linha de montagem automobilística, depois de vários testes, montagens e desmontagens, a última versão do robô foi finalizada: 

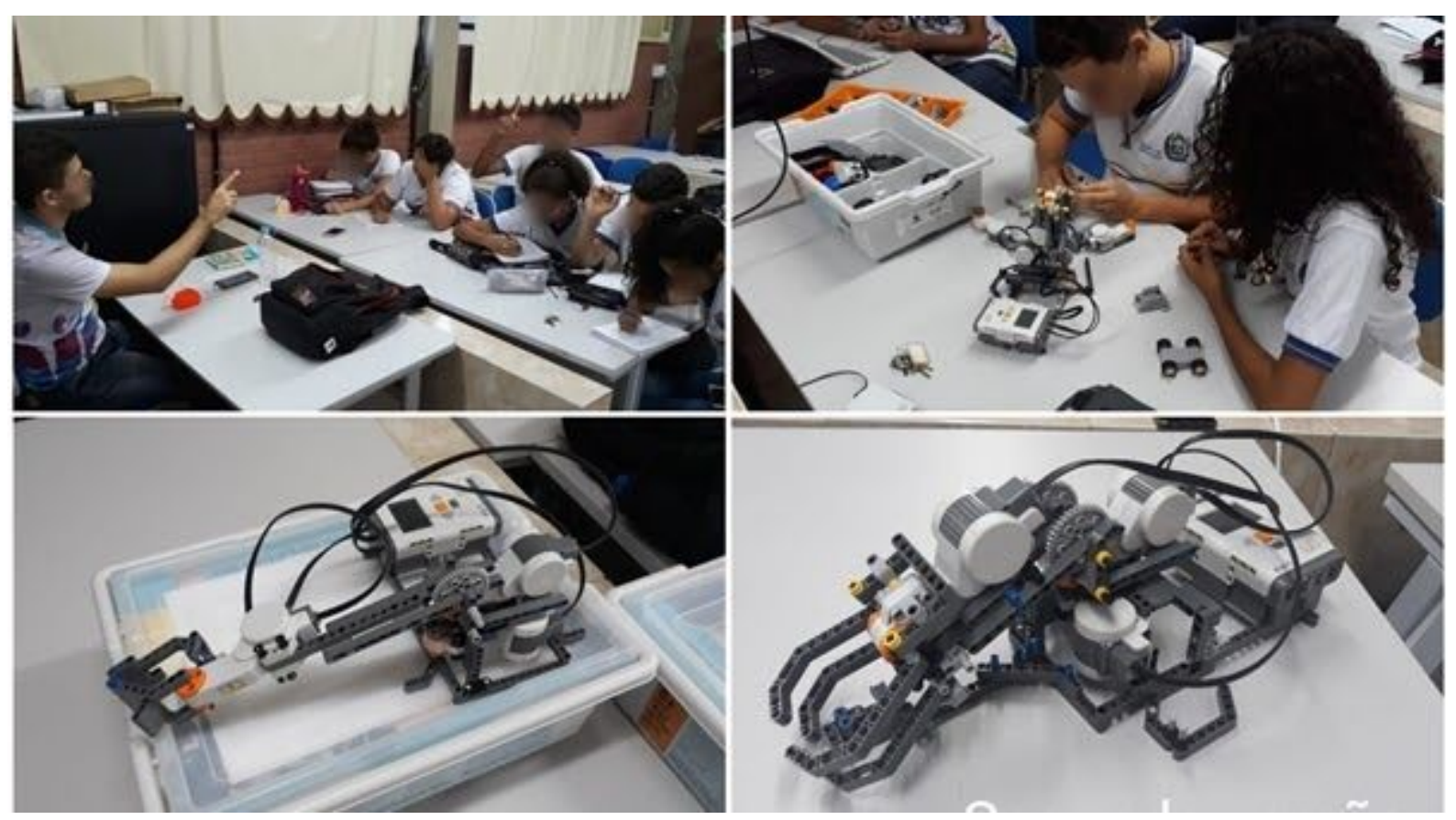

Figura 1. Construção do protótipo da linha de montagem.

Com o robô finalizado demos início a programação do produto do projeto, os alunos fizeram toda a programação do robô utilizando a linguagem em blocos, como é mais intuitiva é bem mais simples de trabalhar com alunos que não possuem afinidade com programação. A programação do robô consiste em pegar duas peças diferentes do automóvel e levá-las a carroceria do carro, encaixando-as na posição correta, a primeira peça já está sendo colocada no local devido e esta parte da programação já foi consolidada, restando ainda a segunda parte da programação.

\subsection{Aplicação do Projeto}

Após a construção e programação do robô passamos para a penúltima fase do projeto, a aplicação, resolvemos aplicar em conjunto com os alunos participantes do projeto nas turmas do $1^{\circ}$ ano $\mathrm{C}$ e $\mathrm{D}$ no período da tarde, visto que era o único horário disponibilizado pelo professor de matemática para a atividade. 


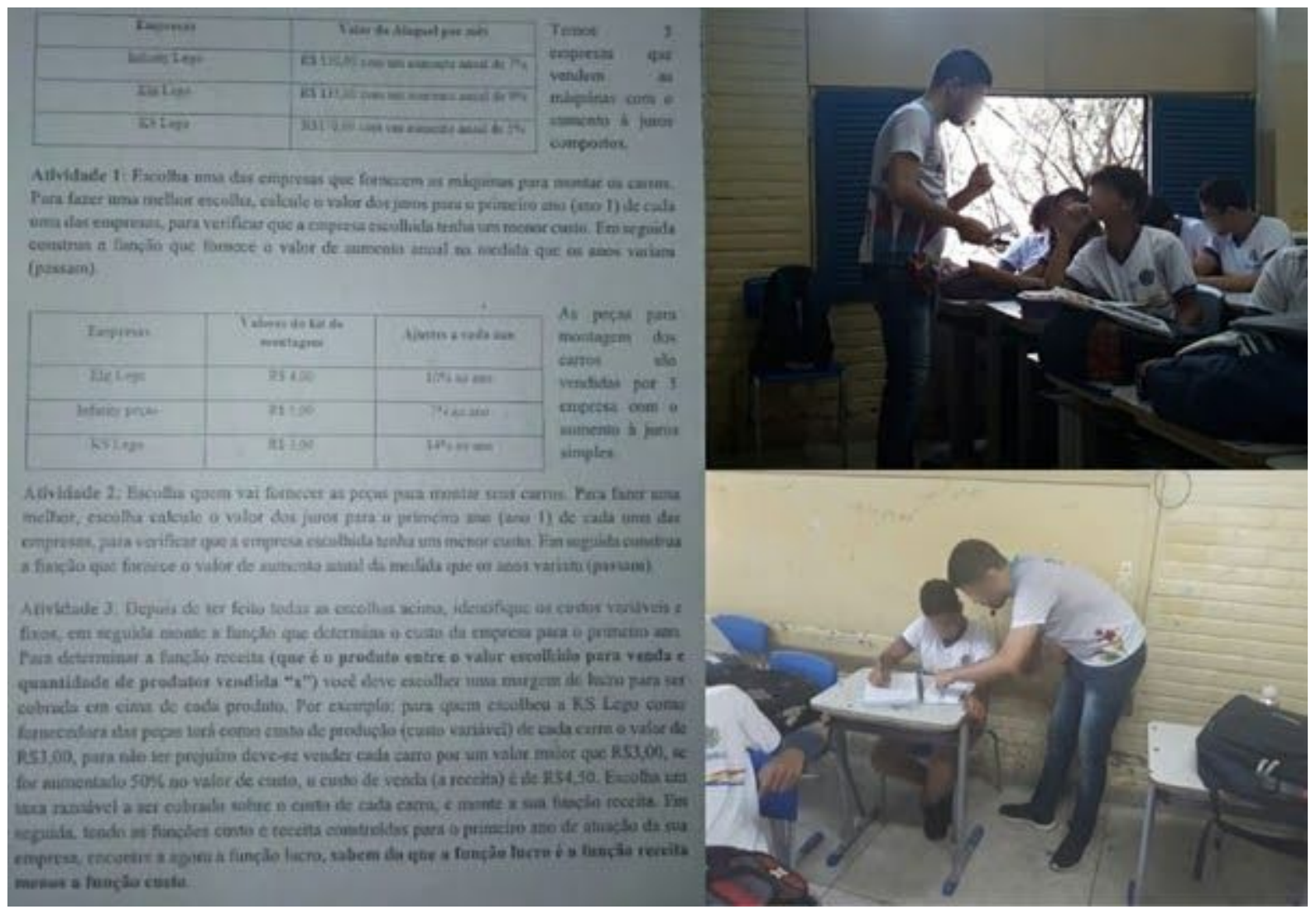

Figura 2. Questões da aplicação e questionamentos sobre a atividade.

A figura 2 exibe as questões da atividade aplicada em sala, bem como o momento da explicação da mesma. Para a execução dos exercícios os alunos foram divididos em duplas, e orientados a escrever suas respostas em uma folha de caderno comum. Um tempo foi dedicado a cada questão, e ao final desse tempo a resposta foi discutida e debatida entre os alunos, levando os estudantes a refletirem sobre as diferentes possibilidades de respostas na escolha de cada empresa fictícia, sendo elas Infinity Lego, Elit Lego e KS Lego.

A primeira questão pede para que os estudantes escolham a melhor empresa para montar os carros, baseando-se no custo do juros de cada uma, para tanto precisam fazer o cálculo do valor dos juros no primeiro ano (ano 1), e em seguida construir uma função que fornece o valor de aumento anual na medida que os anos variam.

$\mathrm{Na}$ segunda questão o estudante escolhe quem vai fornecer as peças para montar seus carros, visando escolher a melhor empresa de fornecimento, os estudantes calcularam o valor do juros para o primeiro ano (ano 1) para cada uma das empresas, e logo após construíram uma função que fornece o valor de aumento anual na medida que os anos variam.

E por último a terceira questão, depois de terem feito todas as escolhas nas questões anteriores, pedimos para que os alunos identificassem os custos variáveis e fixos, em seguida montar a função que determina o custo da empresa para o primeiro ano, bem como a função receita relacionada à empresa escolhida, escolhendo uma margem de lucro para ser cobrada em cima de cada produto. Tendo as funções custo e receita construídas para o primeiro ano de atuação da empresa escolhida pedimos para que encontrassem a função lucro. 
Após a aplicação da atividade os alunos foram convidados a comparecer em outro momento à escola para terem contato com a robótica em si, dado que a infraestrutura não permitiu a aplicação em conjunto com o produto produzido. Nesse outro momento proposto aos alunos, mostramos as utilidades do robô, como funcionava a programação e a movimentação dos motores, e convidamos para participar de oficinas de robótica que serão realizadas na escola por pibidianos de Computação.

\subsection{Oficinas de Robótica}

As oficinas de robótica foram oferecidas aos alunos que se interessaram pelo tema no momento da aplicação, os alunos que se inscreveram tiveram contato direto com os aspectos e dinâmicas da robótica, utilizamos novamente como guia o Manual Mindstorms Education do NXT 2.0 disponibilizado pelos órgãos públicos de Pernambuco.

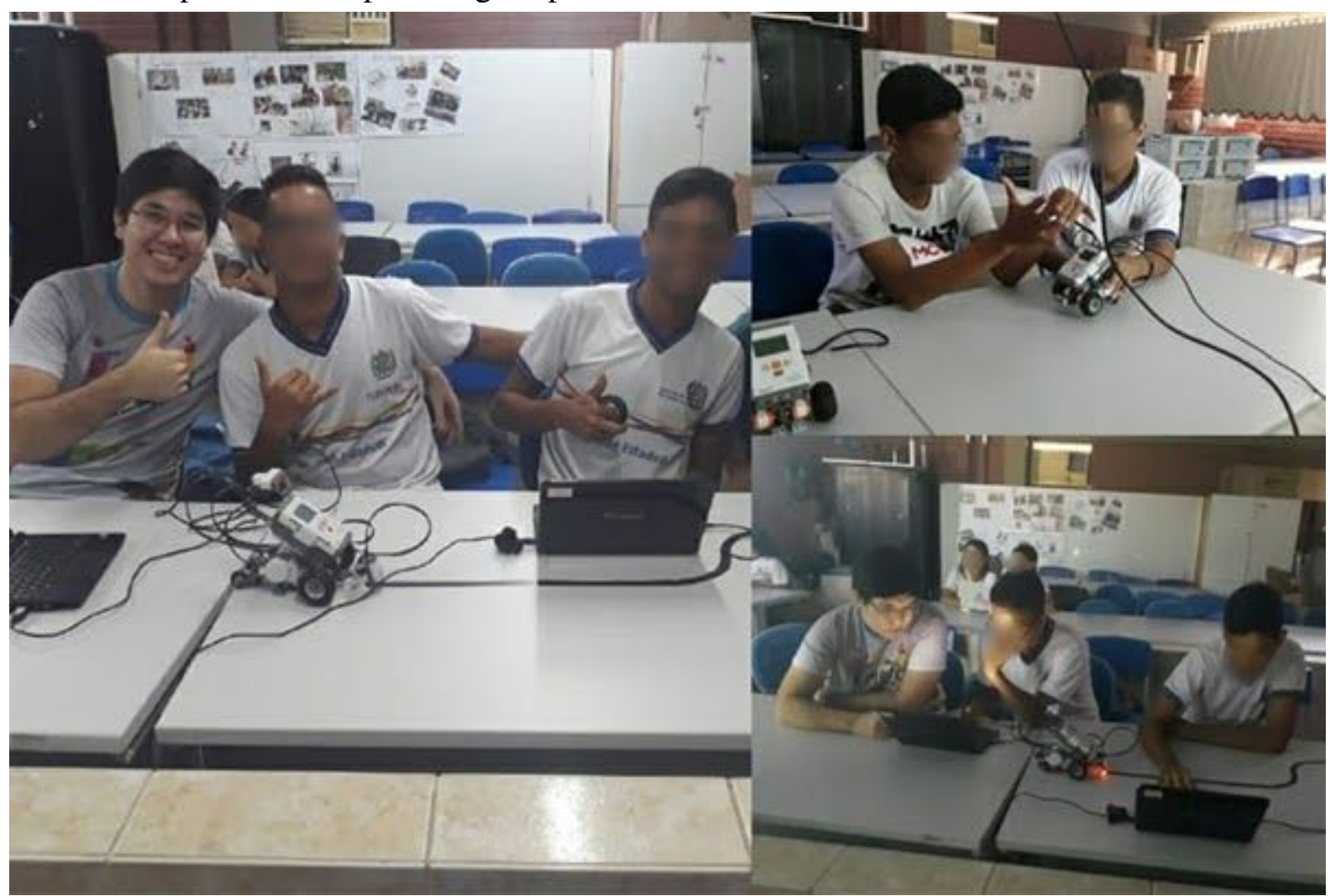

Figura 3. Oficinas de robótica.

Para realizarmos as oficinas nos dividimos em dois grupos, um grupo pela manhã e outro pela tarde, selecionando pequenos grupos de alunos (dois até seis) durante duas semanas, visando abranger e disseminar o máximo de conhecimento ao máximo de alunos. No final dessas semanas conseguimos produzir um robô que é capaz de seguir uma linha preta utilizando o sensor de luminosidade, bem como desviar de obstáculos utilizando um sensor ultrassônico. 


\section{Resultados e Discussões}

Inicialmente, os resultados dos testes de sondagem realizados pelos alunos foram baixos, o que já era esperado, pois os alunos já demonstraram dificuldade em assuntos matemáticos que foram constatados na diagnose e também não possuíam contato com a programação.

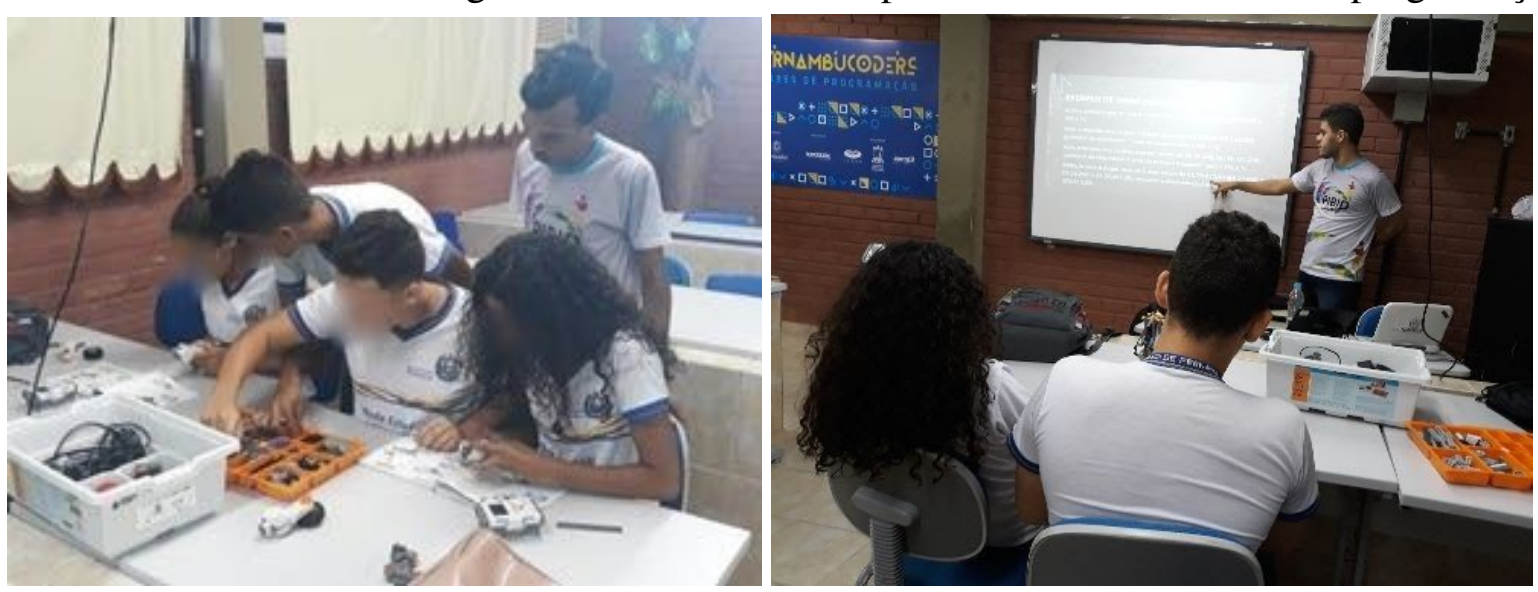

Figura 4. Regência de aulas.

$\mathrm{Na}$ construção do robô nos surpreendeu o interesse dos alunos em explorar novas possibilidades de construção, montando e desmontando tipos diferentes de combinações para a resolução do mesmo problema, com a ajuda do robô educador lego os alunos puderam desbravar esses caminhos, além de resolverem desafios de programação, se preparando para a programação do produto final.

No decorrer das regências de aulas conseguimos perceber um progresso dos alunos em relação aos temas matemáticos e computacionais, aos poucos os alunos conseguiram resolver algumas questões de juros/funções, evoluíram com certa facilidade, e prosseguiram com a programação com destreza, acreditamos que todo esse desempenho surgiu com a dificuldade do tema, despertando o interesse dos alunos, assim como o precursor da robótica educacional afirma, "as crianças, tal como todas as outras pessoas, não preferem a facilidade querem o desafio e o interesse, o que implica dificuldade" (PAPERT, 1996, p. 83-84).

A aplicação do projeto surpreendeu bastante, o trabalho em equipe dos alunos promoveu uma melhora significativa no aprendizado do tema matemático (juros, funções receita, custo e lucro), possibilitando o debate e a reflexão. Comparando os dados da primeira atividade de sondagem e os da aplicação do projeto podemos ter uma noção melhor do possível aprendizado: 


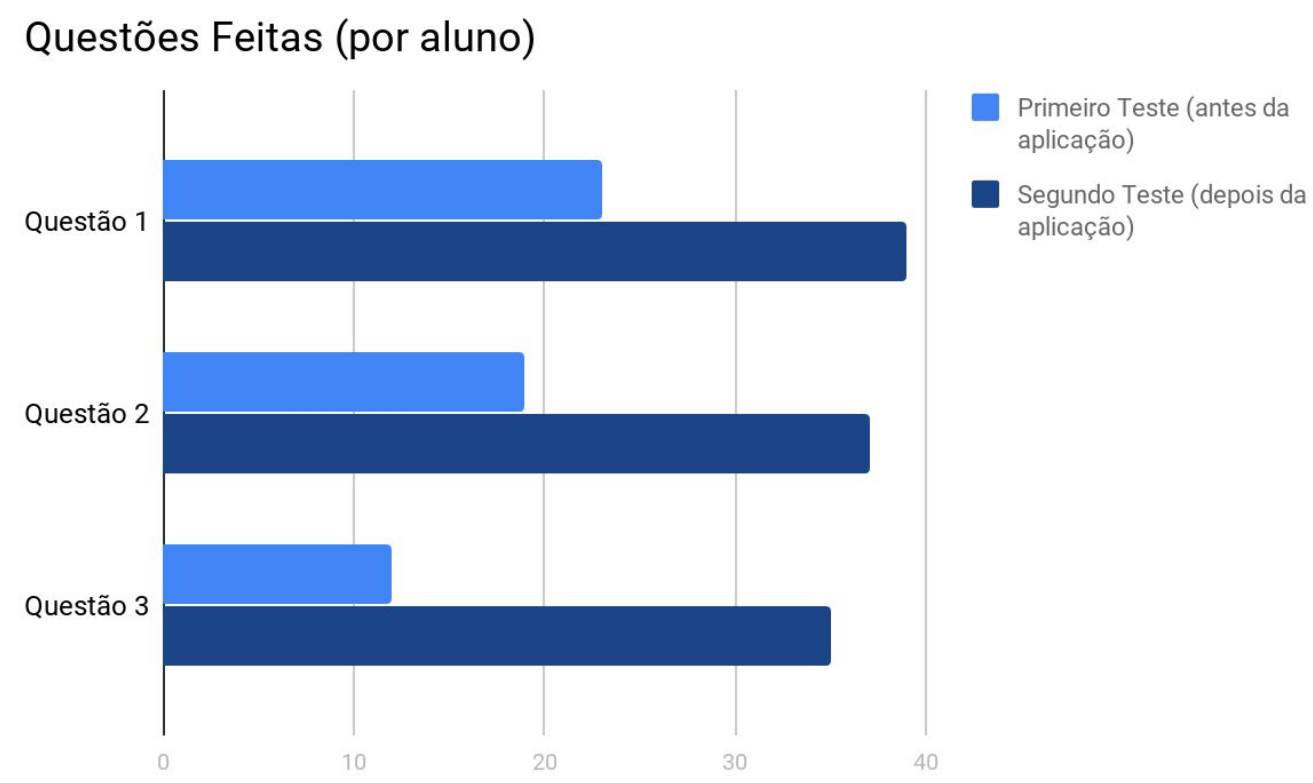

Os alunos apresentaram uma melhora de aproximadamente $42 \%$ na resolução da primeira questão, na segunda questão $46 \%$ e na terceira 59\%. Esses dados nos indicam que apesar de todas as dificuldades os alunos conseguiram entender, ou ao menos replicar o conceito matemático, dado que o aprendizado real é bem mais profundo e necessita de mais tempo para ser consolidado.

\section{Considerações Finais}

O projeto do PIBID possibilitou uma grande experiência na rotina escolar, em contato direto com os alunos, que nos vêem como professores e detentores do conhecimento, mas a realidade é que aprendemos bastante com eles, a ter paciência, a saber respeitar o tempo de aprendizado de cada um e sobretudo ter empatia.

Toda essa vivência no PIBID proporcionou que nós aplicássemos os ensinamentos aprendidos na faculdade aos alunos, de forma mais empática e suave, visando o maior aproveitamento do conhecimento pelos alunos, é esse o diferencial que nos faz gostar mais e mais do caminho que estamos seguindo.

Com certeza toda essa vivência nos vai deixar bons frutos, todo o esforço que tivemos para conseguir algum resultado de aprendizado com os alunos, por menor que seja, já valeu a pena, ao vermos o olhar dos alunos sedentos por aprender nos motiva cada vez mais, confirmando a nossa escolha em sermos profissionais da educação.

\section{Referências Bibliográficas}

BARBOSA, Fernando da Costa et al. Robótica Educacional em Prol do Ensino de Matemática. Anais do Workshop de Informática na Escola, [S.1.], p. 271, out. 2015. ISSN 
2316-6541. Disponível em: <https://www.br-ie.org/pub/index.php/wie/article/view/5037>. Acesso em: 19 set. 2020.

D'AMBROSIO, Ubiratan. Educação matemática: Da teoria à prática. 4 ed. Campinas, SP: Papirus, 1996.

LIRA, Christianne Torres et al. "Construindo gráficos de funções com a robótica educacional". Anais III CONAPESC... Campina Grande: Realize Editora, 2018. Disponível em: <https://www.editorarealize.com.br/artigo/visualizar/43024>. Acesso em: 19 set 2020.

MORAES, Maritza Costa. Robótica educacional: socializando e produzindo conhecimentos matemáticos. 2010. 144f. Dissertação (Mestrado em Educação em Ciências: Química da Vida e Saúde) - Universidade Federal do Rio Grande, Rio Grande, 2010. Disponível em: $<$ http://repositorio.furg.br/handle/1/2864>. Acesso em: 19 set 2020.

MALIUK, K. D. (2009). Robótica Educacional Como Cenário Investigativo Nas Aulas De Matemática. 91 f. Dissertação (Mestrado) - Curso de Programa de Pós-Graduação em Ensino de Matemática, Universidade Federal do Rio Grande do Sul, Porto Alegre.

SBC, Diretrizes para ensino de Computação na Educação Básica. 2019. Disponível em: $<$ https://www.sbc.org.br/educacao/diretrizes-para-ensino-de-computacao-na-educacao-basi ca>. Acesso em: 19 set. 2020.

SILVA, Alan et al. Estimulando o pensamento computacional em alunos do ensino médio com o uso do Scratch for Arduino. Anais do Workshop de Informática na Escola, [S.1.], p. 783, nov. 2019. ISSN 2316-6541. Disponível em: $<$ https://br-ie.org/pub/index.php/wie/article/view/8574/6139>. Acesso em: 19 set. 2020.

PAPERT, Seymour. A Família em Rede: Ultrapassando a barreira digital entre gerações. Tradução de Fernando José Silva Nunes e Fernando Augusto Bensabat Lacerda e Melo. Lisboa: Relógio D’Água Editores, 1996.

WOLFGANG, Meldon et al. "Gaining Robotics Advantage”. BCG, 2017. Disponível em: $<$ https://www.bcg.com/pt-br/publications/2017/strategy-technology-digital-gaining-robotic s-advantage>. Acesso em: 19 set. 2020.

ZILLI, S. do R. (2004). A Robótica educacional no ensino fundamental: perspectivas e prática. 89 f. Dissertação (Mestrado) - Curso de Programa de Pós-Graduação em Engenharia de Produção, Universidade Federal de Santa Catarina, Florianópolis. 